Research Paper

\title{
Characterization saprobic fungi on leaf litter of two species of trees in the Atlantic Forest, Brazil
}

\author{
Loise Araujo Costa, Luís Fernando Pascholati Gusmão \\ Departamento de Ciências Biológicas, Universidade Estadual de Feira de Santana, \\ Feira de Santana, BA, Brazil.
}

Submitted: June 30, 2014; Approved: March 23, 2015.

\begin{abstract}
We investigated the composition and structure of fungal communities associated with leaf litter generated by Clusia nemorosa and Vismia guianensis that belong to phylogenetically-related botanical families and exist together in a remnant of the Atlantic Forest in Bahia, Brazil. Samplings were conducted during wet (June2011) and dry (January2013) seasons in Serra da Jibóia. The fungi were isolated using particle filtration and the 1,832 isolates represented 92 taxa. The wet season yielded the largest number of isolates $(1,141)$ and taxa $(76)$ compared with the dry season $(641$ isolates and 37 taxa).The richness and diversity of fungal species associated with C. nemorosa (64 taxa, Simpson $=0.95$ ) were higher compared with those of $V$. guianensis (59 taxa, Simpson $=0.90$ ). Analysis of similarity (ANOSIM) revealed significant variations in the composition and community structure of fungi isolated from the two plants as a function of seasons. In contrast, nonmetric multidimensional scaling (NMDS) analysis show that the seasonality was an important influence on the distribution of fungal species. However, the populations of the saprobic fungal communities were dynamic, and several factors may influence such communities in the Atlantic Forest.
\end{abstract}

Key words: fungal communities, seasonality, rainforest, diversity, fungal ecology.

\section{Introduction}

The Atlantic Forest comprises a great diversity of plants, estimated at approximately 20,000 species, including 8,000 that are endemic (Myers et al., 2000; SOS Mata Atlântica, 2013). This biome is home to one of the largest concentrations of species per square meter on the planet (Thomas et al., 1998). Despite this robust biodiversity, the Atlantic Forest suffers major threats, and only $11.7 \%$ of its original area remains (Ribeiro et al., 2009). Therefore, it is considered one of the 34 global hotspots (Morris, 2010).

As in other forest ecosystems, litter deposited on the soil of the Atlantic Forest comprises various plant debris, and leaves represent the most significant component (Werneck et al., 2001). Fungi, among other microorganisms, contribute significantly to decomposition through their ability to degrade numerous compounds produced by plants, and the diversity of leaves in the litter allows the coexistence of various species (Promputtha et al., 2010;
Vorísková and Baldrian, 2013). This plurality is due, in part, to the recurrence of fungal species of certain host plants (Santana et al., 2005; Paulus et al., 2006b; Pasqualatti et al., 2014) and particular stages of decomposition (Cornejo et al., 1994; Yanna et al., 2001; Santhi and Vittal, 2012).

Zhou and Hyde (2001) suggested the term "recurrence" to replace the specific terms and preferences commonly used to describe interactions of saprobic fungi that occur most often in association with a particular plant species compared with other species in the same environment. The reasons for the recurrence of fungi on different hosts may involve foliar structure and chemistry (Santana et al., 2005; Paulus et al., 2006b) or the initial decomposition of litter by the action of persistent endophytes present in the tissues of living leaves when they subsequently senesce and fall to the ground (Hyde et al., 2007; Promputtha et al., 2010; Unterseher et al., 2013; Allegrucci et al., 2014). Besides the recurrence of fungi harbored by particular plants, 
abiotic factors such as climate at collection sites and seasonality influence the composition and structure of fungal communities (Polishook et al., 1996; Ormeño et al., 2006; Paulus et al., 2006b; Allegrucci et al., 2014).

Numerous studies demonstrate the recurrence of saprobic fungi on substrates of decomposing plants, and fungi tend to recur at a higher rate according to the host's genus (Polishook et al., 1996; Paulus et al., 2006b; Kodsueb et al., 2008; Cheewangkoon et al., 2009; Magalhães et al., 2011; Allegrucci et al., 2014). For example, Paulus et al. (2006b) investigated the community of fungi associated with six plants and found low overlap among species, which may be accounted for by the phylogenetically unrelated families to which the host plants belong. Further, Paulus et al. (2006b) analyzed the influence of seasonality (wet and dry seasons) on the distribution of fungi and found that the taxonomy of the substrate was the most important variable. We are unaware of studies that determined whether saprobic fungi recur on a specific host or are generally present in the leaf litter of plants of phylogenetically related families.

To estimate the number of fungal species, it is important to determine whether fungi are recurrent or general, particularly in tropical regions (Zhou and Hyde, 2001; Hawksworth, 2001). The goals of the present study were as follows: (1) to investigate the composition and structure of the fungal community of plants in the same environment and (2) to evaluate the effects of plant species and seasonal- ity in a diverse biological community. For this purpose, we identified the fungi associated with leaf litter of Clusia nemorosa G. Mey (Clusiaceae) and Vismia guianensis (Aubl) Choisy (Hypericaceae), which are locally abundant and belong to phylogenetically-related botanical families, during the wet and dry seasons in a remnant of Atlantic Forest.

\section{Material and Methods}

\section{Study area and sampling}

The Serra da Jibóia is located in South Reconcavo in the State of Bahia and consists of a complex of hills and mountains that is distributed over six municipalities (Santa Terezinha, Castro Alves, Elísio Medrado, Varzedo, São Miguel das Matas and Laje) (Figure 1). Expeditions were conducted in Morro da Pioneira (north of the Serra da Jibóia), in the municipality of Santa Terezinha (12 $51^{\prime} \mathrm{S}$ and $39^{\circ} 28^{\prime} \mathrm{W}$ ) (Figure 1 ). The mean altitude of this area ranges between $750-840 \mathrm{~m}$ above sea level with a mean annual temperature and rainfall of $21^{\circ} \mathrm{C}$ and 1,200 mm. Rainfall occurs most abundantly from April through July (Neves, 2005; Tomasoni MA, unpublished data). The remaining months are called dry months, because they are characterized by levels of precipitation $<100 \mathrm{~mm}$. To evaluate the influence of seasonality on the community of fungi, we performed sampling during wet and dry seasons

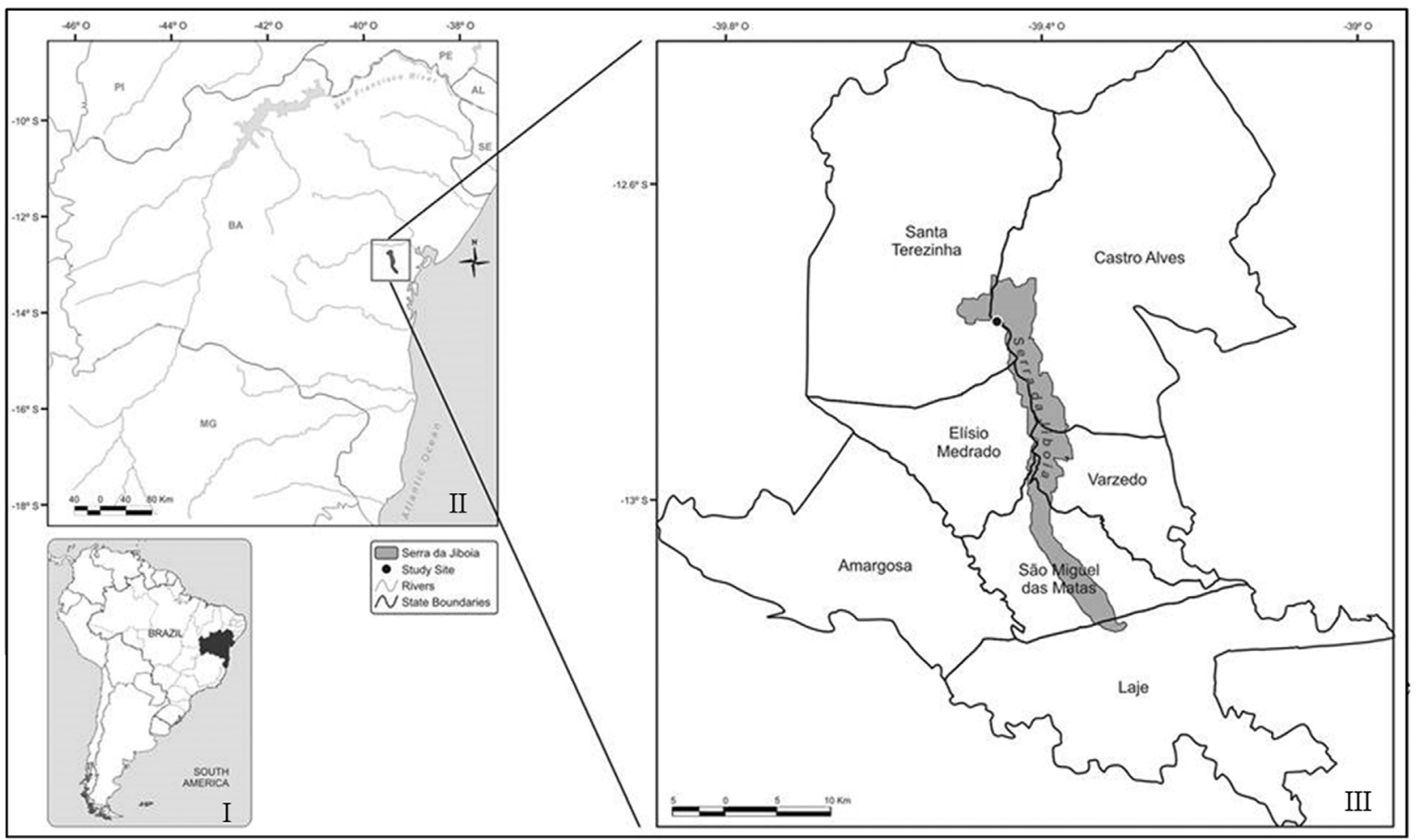

Figure 1 - Location of the Serra da Jibóia in the state of Bahia, Brazil (I, II); and collection site in the municipality of Santa Terezinha (Morro da Pioneira) indicated by the black point on the map (III). 
(considering the average rainfall of three months before collection, $114.5 \mathrm{~mm}$ and $53.16 \mathrm{~mm}$, respectively).

The sampled plants are shrubs and the height reaches approximately $3 \mathrm{~m}$. Samples of C. nemorosa (C1: S $12^{\circ} 51^{\prime} 19^{\prime \prime}$ and W 39 $28^{\prime} 32^{\prime \prime}$; C2: S 12'51'21" and W

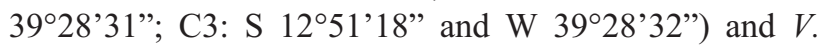
guianensis (V1: S 12 ${ }^{\circ} 50^{\prime} 57,3^{\prime \prime}$ and W $39^{\circ} 28^{\prime} 33,0^{\prime \prime}$; V2: S $12^{\circ} 50^{\prime} 53,8^{\prime \prime}$ and W $39^{\circ} 28^{\prime} 31,4^{\prime \prime}$; V3: S $12^{\circ} 50^{\prime} 51,7^{\prime \prime}$ and W $\left.39^{\circ} 28^{\prime} 30^{\prime \prime}\right)$ were chosen, taking into account the presence and amount of fallen leaves at their bases, and were marked for subsequent collection. One sample of each individual plant comprising 10 leaves were collected during each expedition, and 60 leaves of each plant species (30 each from wet and dry seasons) were processed no longer than $24 \mathrm{~h}$ after collection. A sample of C. nemorosa dry (C3d) was lost due to contamination and not considered in the analysis.

\section{Isolation, characterization and preservation of fungi}

The leaves were first washed with running water and then subjected to surface disinfection according to the method of Paulus et al. (2003a). Because the leaves of $V$. guianensis are smaller compared with those of $C$. nemorosa, leaf areas were standardized after disinfection. The leaves of $C$. nemorosa were divided into five areas and were removed by drawing a section equivalent to the leaf area of $V$. guianensis $\left(18 \mathrm{~cm}^{2}\right)$. Particle filtration described by Bills and Polishook (1994), with modifications, was used to isolate fungi.

Each sample was homogenized in a blender for $1 \mathrm{~min}$ in $100 \mathrm{~mL}$ of sterile distilled water. The particulate material was washed with distilled water jets and filtered through a group of five stainless steel meshes with decreasing openings $(1.0,0.7,0.5,0.25$, and $0.18 \mathrm{~mm})$. The particles retained on the mesh of the smallest opening were transferred to centrifuge tubes and suspended in sterile distilled water $(50 \mathrm{~mL})$, vortexed for $1 \mathrm{~min}$, and decanted. The supernatant was discarded, and the tube was filled with sterile distilled water to a volume of $50 \mathrm{~mL}$. This procedure was performed four times, and the residual material was suspended in $20 \mathrm{~mL}$ of sterile distilled water. Aliquots $(50 \mu \mathrm{L})$ of the suspension were transferred and inoculated in triplicate, using a Drigalsky stirring rod, into $90-\mathrm{mm}$ diameter Petri dishes containing dichloran rose bengal chloramphenicol agar (DRBC, without the addition of dichloran) and malt yeast extract agar (MYE) supplemented with rose bengal $(25 \mathrm{mg} / \mathrm{L})$ and chloramphenicol (100 mg/L) (Paulus et al., 2003a).

The plates were incubated at room temperature and light. Mycelial growth was observed daily from days 2-30, and after verification of hyphal growth, the particles were transferred to 60-mm diameter Petri dishes filled with culture medium containing corn-meal carrot agar (CastañedaRuiz, personal communication) and fragments of sterilized banana leaves $\left(3 \mathrm{~cm}^{2}\right)$ to induce sporulation (Paulus et al., 2003b).
Pure cultures were examined periodically using a stereomicroscope until reproductive structures were observed. These structures were transferred with the aid of a fine needle to slides with mounting medium containing PVL resin (polyvinyl alcohol lactic + alcohol + phenol) (Trappe and Schenk, 1982) and lactic acid. Fungi were identified morphologically, and the structures of taxonomic importance were compared with those described in the relevant basic and specific literature.

Isolates that did not sporulate were subsequently cultured in water agar (WA) and oatmeal agar (OA) with fragments of sterilized banana leaves. Sterile mycelia were grouped into morphotypes according to characteristics such as growth rate, margin shape, surface staining and reverse, lift and texture of the mycelia, and pigment production in the culture medium (Lacap et al., 2003). Isolates of each identified species were preserved under mineral oil (Buell and Weston, 1947) and Castellani (1967) and deposited in the Coleção de Culturas de Microrganismos da Bahia (CCMB), Universidade Estadual de Feira de Santana.

\section{Data analyses}

Community diversity of saprobic fungi of both plant species was evaluated using Simpson's diversity index (Magurran, 1988). The number of taxa expected in the communities was calculated using the Chaol estimator (Chao, 1984). The differences in richness among fungi isolated from C. nemorosa and $V$. guianensis were determined using rarefaction curves (Magurran, 1988). Similarities in species composition between the samples of leaf litter were verified by ordering the data using the NMDS method (Nonmetric Multidimensional Scaling) (Kruskal, 1964) from the Bray-Curtis dissimilarity matrix. The ANOSIM (Analysis of Similarity one way) permutation test was used to assess differences/dissimilarity between groups of samples (Clarke, 1993). SIMPER (Similarity Percentages) analysis was performed to identify the most influential species and those that contributed most to the dissimilarity between groups (Clarke, 1993). The analyses were conducted using Biodiversity Pro 2 (Mc Aleece, 1997), PAST v. 3.01 (Hammer et al., 2013) and R 3.0.1 (R Core Team, 2013).

\section{Results}

We isolated 1,832 species of fungi representing 92 taxa from the leaf litter of $C$. nemorosa and $V$. guianensis. The greatest number of fungi $(1,141)$ and the richness of taxa (76) were observed during the wet season (Table 1). The Simpson's index (1-D) for communities of fungi demonstrated higher diversity of that one isolated from $C$. nemorosa (0.95) compared with $V$. guianensis $(0.90)$. The confidence intervals indicated that the difference between the indices, although small, was statistically significant, because there was no overlap between values. Considering the same sampling effort, the estimated richness obtained 
using Chao 1 was 70 taxa for $C$. nemorosa and 66 taxa for $V$. guianensis (Table 1).

Fewer fungi (869) with the highest richness of taxa (64) were isolated from C. nemorosa. During the wet season, the leaves of $C$. nemorosa harbored more taxa (54), and the leaves of $V$. guianensis harbored a greater richness of species (31) during the dry season (Table 1 and Figure 2). Rarefaction curves showed no stability; however, the slopes of the curves of samples collected during the dry season were shallower (Figure 2). Given the smaller sample size of 291 isolates used to perform a random resampling, the expected values of richness displayed by the rarefaction curves were $45,38,28$, and 20 for samples $\mathrm{Cw}, \mathrm{Vw}, \mathrm{Cd}$, and $\mathrm{Vd}$, respectively (Figure 2). However, the differences observed between $\mathrm{Cw}$ and $\mathrm{Vw}$ were not significant, because there was overlap between confidence intervals (Cw: 41-49; Vw: 34-42).

Among the sporulating isolates, 68 taxa were asexual (13 coelomycetes and 55 hyphomycetes), and nine pro- duced sexual reproductive structures in culture. Four ascomycetes formed connections with their asexual forms as follows: Calonectria gracilipes/Cylindrocladium graciloideum, Glomerella cingulata/Colletotrichum gloeosporioides, Guignardia sp./Phyllosticta sp. and Pseudomassaria carolinensis/Beltraniella portoricensis. Taxa Pestalotiopsis spp. (14.2\%), P. carolinensis (12.5\%), Chaetosphaeria sp. (6.6\%), G. cingulata (6.6\%), B. rhombica (6.3\%), sterile mycelium sp.7 (6.1\%), Penicillium minioluteum (3.7\%), and Phomopsis sp.2 (3.2\%) were the most abundant and common in both substrates, and the first four taxa were most prevalent on $V$. guianensis (Table 2).

Clusia nemorosa harbored 33 unique taxa and $V$. guianensis yielded 28 taxa. Thirty-one taxa were shared between the two plants (34\%), and $66 \%$ did not overlap. Among taxa shared between $C$. nemorosa and $V$. guianensis, the most abundant were B. rhombica, Chaetosphaeria sp., G. cingulata, sterile mycelium sp.6, P.

Table 1 - Richness, number of isolates, Simpson's diversity, and Chao1 of the fungal communities from leaves of $C$. nemorosa and $V$. guianensis during the wet (w) and dry (d) seasons in the Serra da Jibóia, Bahia, Brazil.

\begin{tabular}{|c|c|c|c|c|c|c|c|c|}
\hline \multirow[t]{2}{*}{ Substrates } & \multicolumn{2}{|c|}{$\mathrm{N}^{\circ}$ isolates } & \multirow[t]{2}{*}{ Total } & \multicolumn{2}{|c|}{ Richnes } & \multirow[t]{2}{*}{ Total } & \multirow[t]{2}{*}{ Simpson $^{\mathrm{a}}$} & \multirow[t]{2}{*}{ Chaol $^{\mathrm{a}, \mathrm{b}}$} \\
\hline & $\mathrm{w}$ & $\mathrm{d}$ & & $\mathrm{w}$ & $\mathrm{d}$ & & & \\
\hline C. nemorosa & 578 & 291 & 869 & 54 & 20 & 64 & $0.95(0.94-0.96)$ & $70(65-88)$ \\
\hline V. guianensis & 563 & 400 & 963 & 45 & 31 & 59 & $0.90(0.89-0.91)$ & $66(57-101)$ \\
\hline Total & 1141 & 691 & 1832 & 76 & 37 & 92 & $0.94(0.93-0.95)$ & $98(94-114)$ \\
\hline
\end{tabular}

${ }^{\mathrm{a}} 95 \%$ confidence intervals.

${ }^{\mathrm{b}}$ Analysis performed with 5 samples for each plant.



Figure 2 - Rarefaction curves of fungi isolated from leaves of C. nemorosa $(\mathrm{C})$ and $V$. guianensis $(\mathrm{V})$ during the wet $(\mathrm{w})$ and dry (d) seasons in the Serra da Jibóia, Bahia, Brazil. 
Table 2 - Number of fungi associated with leaf litter of C. nemorosa and V. guianensis collected during the wet (w) and dry (d) seasons in the Serra da Jibóia, Bahia, Brazil.

\begin{tabular}{|c|c|c|c|c|c|}
\hline \multirow[t]{2}{*}{ Taxa } & \multicolumn{2}{|c|}{ C. nemorosa } & \multicolumn{2}{|c|}{ V. guianensis } & \multirow[t]{2}{*}{ Total } \\
\hline & $\mathrm{w}$ & $\mathrm{d}$ & $\mathrm{w}$ & $\mathrm{d}$ & \\
\hline Pestalotiopsis spp. & 86 & 0 & 174 & 0 & 260 \\
\hline Pseudomassaria carolinensis M.E. Barr \& Hodges & 62 & 1 & 100 & 67 & 230 \\
\hline Chaetosphaeria sp. & 24 & 1 & 65 & 31 & 121 \\
\hline Glomerella cingulata (Stoneman) Spauld. \& H. Schrenk & 36 & 0 & 25 & 60 & 121 \\
\hline Beltrania rhombica Penz. & 52 & 0 & 18 & 46 & 116 \\
\hline Sterile mycelium sp.6 & 5 & 91 & 14 & 2 & 112 \\
\hline Penicillium minioluteum Dierckx & 0 & 31 & 0 & 37 & 68 \\
\hline Phomopsis sp.2 & 4 & 31 & 3 & 20 & 58 \\
\hline Gliocladiopsis sp. & 49 & 0 & 0 & 0 & 49 \\
\hline Phomopsis sp.4 & 22 & 24 & 0 & 0 & 46 \\
\hline Dactylaria belliana B.C. Paulus, Gadek \& K.D. Hyde & 41 & 0 & 0 & 0 & 41 \\
\hline Satchmopsis brasiliensis B. Sutton \& Hodges & 0 & 0 & 2 & 38 & 40 \\
\hline Guignardia sp. & 0 & 28 & 0 & 7 & 35 \\
\hline Penicillium brevicompactum Dierckx & 16 & 0 & 18 & 0 & 34 \\
\hline Sterile mycelium sp.7 & 2 & 10 & 6 & 14 & 32 \\
\hline Phomopsis sp.1 & 0 & 18 & 5 & 8 & 31 \\
\hline Rare taxa $\mathrm{a}^{\mathrm{a}}$ & 179 & 56 & 133 & 70 & 438 \\
\hline Total & 578 & 291 & 563 & 400 & 1832 \\
\hline
\end{tabular}

a Fungal isolates present at a frequency of $<1.5 \%$ were as follows: Acremonium spp.1 and 2, Ardhachandra cristaspora, ascomycetes spp.1-5, Aspergillus ochraceus, Atrosetaphiale fragelliformis, Bartalinia $\mathrm{cf}$. robillardoides, Beltraniella $\mathrm{cf}$. botryospora, Calonectria gracilipes, coelomycetes sp., cf. Chaetosphaeronema sp.1, Chalara alabamensis, Chalara cf. paramontellica, Cladosporium-like sp.1, Coleophoma sp., Cryptophialoidea fasciculata, Curvularia geniculata, Cylindrocladium candelabrum, Cylindrocladium floridanum, Cylindocladium gracile, Cylindrocladium pauciramosum, Dactylaria cf. acerosa, Dactylaria cf. biseptata, Dictyochaeta simplex, Dinemasporium sp., Fusarium lateritium, Fusarium solani, Gyrotrix cf. pediculata, hifomiceto sp.1-3, Idriella $\mathrm{cf}$. cubensis, Idriella lunata, Idriella ramosa, Idriella $\mathrm{cf}$. variabilis, Idriella spp.1 and 2, Lasiodiplodia theobromae, Menisporopsis theobromae, Metarhizium anisopliae, sterile mycelia spp. 1-5 and 8-15, Ochroconis variabilis, Ochroconis spp.1 and 2, Paliphora intermedia, Parasympodiella laxa, Phomopsis sp.3, Pyrenochaeta sp., Sclerostagonospora sp., Scolecobasidiella cf. tropicalis, Speiropsis scopiformis, Stachybotrys chartarum, Subulispora longirostrata, Thozetella cristata, Thozetella gigantea, Vermicullariopsiella immersa, Verticillium sp., Volutella minima, Wiesneriomyces laurinus, Zygosporium mansonii.

carolinensis, P. minioluteum, Pestalotiopsis spp., and Phomopsis sp.2. Some of these fungi such as B. rhombica, P. minioluteum and Phomopsis sp.2 were isolated almost with the same frequency, while others such as Chaetosphaeria sp., G. cingulata, sterile mycelium sp.6, and $P$. carolinensis were more frequent in the leaves of one plant. Some fungi were unique, such as Gliocladiopsis sp., Phomopsis sp.4, and Dactylaria belliana isolated from $C$. nemorosa, and Satchmopsis brasiliensis, Beltraniella cf. botryospora, and sterile mycelium sp.13 isolated from $V$. guianensis. About climate seasons existed differences in community composition with the fungi Chaetosphaeria sp., P. brevicompactum, P. carolinensis, and Pestalotiopsis spp. associated with the wet season exclusively or most often, while Guignardia sp., P. minioluteum, Phomopsis sp.2, and sterile mycelium sp.7 were associated predominantly or solely with the dry season (Table 2).

ANOSIM analysis indicated a significant difference in community compositions of fungi associated with the leaves of $C$. nemorosa or $V$. guianensis and between sea- sons $(\mathrm{R}=0.8, \mathrm{P}=0.0004)$. NMDS analysis revealed a strong separation between samples collected during the wet (left) and dry (right) seasons as well as between $C$. nemorosa (top) and $V$. guianensis (lower) (Figure 3).

SIMPER analysis indicated greater dissimilarity between communities of $C$. nemorosa during the wet and dry seasons, and the taxa that contributed most were Pestalotiopsis spp. and sterile mycelium sp.6. The lowest dissimilarity was observed between the communities of $C$. nemorosa and $V$. guianensis during the wet season, and the taxon Pestalotiopsis spp. made an important contribution (Table 3).

\section{Discussion}

Using the technique of particle filtration, we report here the isolation of a large number of fungi from the leaf litter of $C$. nemorosa and $V$. guianensis in from the Atlantic Forest of Brazil during wet and dry seasons. This approach favors the isolation of fungi that grow slowly by reducing 


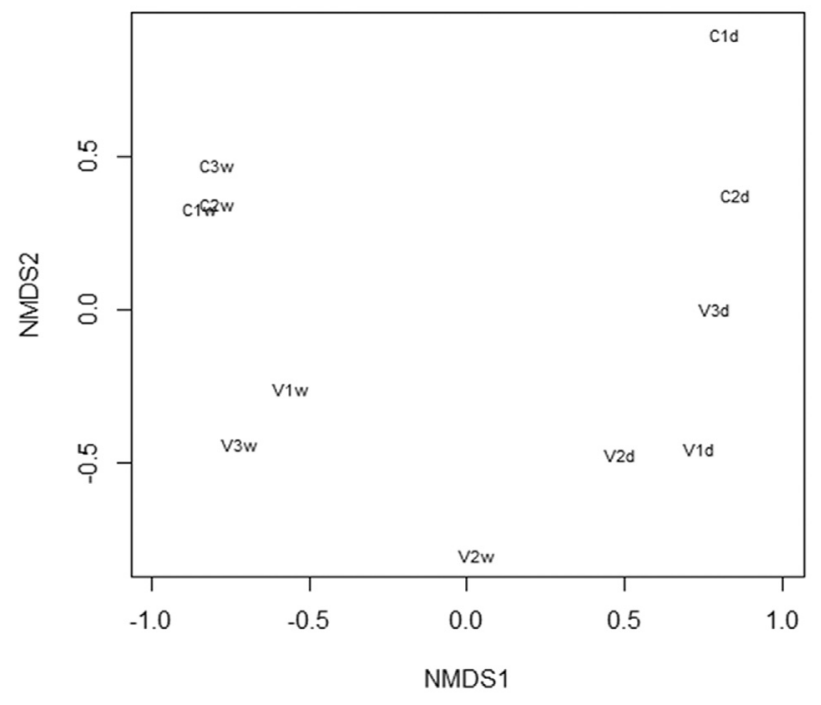

Figure 3 - Two-dimensional ordering using NMDS of communities of fungi associated with leaf litter of C. nemorosa $(\mathrm{C})$ and $V$. guianensis (V) during the wet (w) and dry (d) seasons in the Serra da Jibóia, Bahia, Brazil. Stress $=0.06$.

the plant substrate to particles with lengths of a few micrometers that theoretically harbor one fungus per particle, thereby decreasing competition between fungi and increasing the contact surface of the substrate with the culture medium (Kirby et al., 1990; Bills and Polishook, 1994).

The species of fungi isolated from the leaves of $C$. nemorosa was richer and more diverse, although fewer samples were analyzed (05 samples), compared with those isolated from $V$. guianensis (06 samples). The characteristics of the leaves of both plants are distinct. For example, the leaves of $C$. nemorosa are thicker, and those of $V$. guianensis are thinner and brittle. A positive correlation between the richness of fungi and leaf thickness was demonstrated by Paulus et al. (2006b), who found a greater number of species of fungi associated with the leaves of Cryptocarya mackinnoniana that are thicker compared with the other leaves analyzed such as Darlingia ferruginea and Elaeocarpus angustifolius. This correlation may be attributed to the larger volume of available substrate for mycelial growth. Other features that were not evaluated in the present study, such as foliar area and chemistry, contribute alone or together to the growth of fungi in leaf litter (Santana et al., 2005; Paulus et al., 2006b). The lower Simpson's diversity observed for community isolated from $V$. guianensis was associated with higher frequencies of taxa such as $P$. carolinensis and Pestalotipsis spp, which are present most frequently in the leaves of many trees in tropical forests (Bills and Polishook, 1994; Paulus et al., 2006).

We isolated more taxa during the wet season compared with the dry season (76 and 37, respectively). Comparing the communities of fungi according to season, those of wet season showed greater richness in C. nemorosa (54) and those of dry season showed greater richness in $V$. guianensis (31). Precipitation is considered a key environmental factor for the spread of fungi and the decomposition

Table 3 - Analysis of the percentage similarity (SIMPER) of fungal communities isolated from leaf litter of C. nemorosa (C) and V. guianensis (V) during the wet (w) and dry (d) seasons in the Serra da Jibóia, Bahia, Brazil.

\begin{tabular}{|c|c|c|c|}
\hline Samples & Average dissimilarity (SIMPER in \%) & Promoting species dissimilarity & Contribution $(\%)$ \\
\hline \multirow[t]{3}{*}{$\mathrm{Cw} \times \mathrm{Cd}$} & 91 & Pestalotiopsis spp. & 10.87 \\
\hline & & sterile mycelium sp. 6 & 10.87 \\
\hline & & P. carolinensis & 7.7 \\
\hline \multirow[t]{3}{*}{$\mathrm{Cw} \times \mathrm{Vw}$} & 50.4 & Pestalotiopsis spp. & 15.3 \\
\hline & & Gliocladiopsis sp. & 8.5 \\
\hline & & D. belliana & 7.1 \\
\hline \multirow[t]{3}{*}{$\mathrm{Cw} \times \mathrm{Vd}$} & 62.1 & Pestalotiopsis spp. & 14.1 \\
\hline & & Gliocladiopsis sp. & 8.1 \\
\hline & & D. belliana & 6.7 \\
\hline \multirow[t]{3}{*}{$\mathrm{Cd} \times \mathrm{Vw}$} & 90.4 & Pestalotiopsis spp. & 22.5 \\
\hline & & P. carolinensis & 12.8 \\
\hline & & sterile mycelium sp.6 & 10 \\
\hline \multirow[t]{3}{*}{$\mathrm{Cd} \times \mathrm{Vd}$} & 74.8 & sterile mycelium sp.6 & 17.2 \\
\hline & & P. carolinensis & 12.7 \\
\hline & & G. cingulata & 11.6 \\
\hline \multirow[t]{3}{*}{ Vw x Vd } & 64.3 & Pestalotiopsis spp. & 28.1 \\
\hline & & P. minioluteum & 6 \\
\hline & & S. brasiliensis & 5.8 \\
\hline
\end{tabular}


of organic matter (Cannon and Sutton, 2004). For example, under high humidity, the decaying plant debris are more densely colonized by fungi (Paulus et al., 2006b), particularly because the leaves represent the most significant part of the litter and contribute greater biomass and nutrients compared with other plant substrates (Vorísková and Baldrian, 2013).

The species composition of communities was influenced by the seasons. For example, Pestalotiopsis spp. and $P$. brevicompactum were present only in the wet season in the leaf litter from both plants, and $P$. minioluteum and Guignardia sp. were associated only with the dry season. The characteristics of the types of sporulation (dry or wet spores) and the morphologies of conidia may be related to the dispersion medium or adhesion to the substrate (Jones, 2006). Pestalotiopsis species produce asexual spores with terminal appendages and are retained in a damp mass. Both features enhance the adhesion of spores to the substrate surface so that sporulation and dispersion depend on high humidity (Nag Raj, 1993; Jones, 2006). Rainfall influences the distribution of Guignardia ascospores, because they are transported by air currents over long distances and are therefore influenced by rainfall. In the present study, the majority of specimens were in their asexual stage, known as Phyllosticta, whose spores have a mucilage, which protects against desiccation in an adverse environment (Kriel et al., 2000). In contrast, Penicillium comprises species that produce dry spores that are efficiently dispersed by wind (Cannon and Sutton, 2004).

Rarefaction curves did not reach stability due to the large number of fungi isolated by the particle filtracion. The slope of the rarefaction curve for samples acquired during the dry season was shallower, demonstrating that the collection effort was satisfactory. However, the data for samples collected during the wet season indicate that new collections may increase the number of taxa. Therefore, regardless of the representation of plant species, the community present during the wet season always comprised greater numbers of isolates and species richness (Figure 2). Considering the overall communities of fungi, the richness estimated using Chaol approached the number of taxa observed, indicating that the techniques used for sampling and isolating fungi were efficient.

Polishook et al. (1996) observed similar percentages of similarity and complementarity (26-32\% and 68-74\%, respectively) among the communities of saprobic fungi of Manilkara bidentata and Guarea guidonia in a tropical rainforest in Puerto Rico to those reported here for the Atlantic Forest. Santana et al. (2005) found distinct communities among five plant species, with a complementary level of $68 \%$ for the 10 most frequently isolated fungi. Monkai et al. (2013) reported very low levels of similarity between the communities of Magnolia liliifera and Cinnamomum iners, reaching values of $1.92 \%$ to $8.51 \%$, considering species and genus, respectively. Pasqualetti et al. (2014) inves- tigated the fungi of 17 species of trees in Mediterranean areas and observed communities with variable percentages of overlapping species (6-47\%). However, when the community of fungi between species of the same genus was investigated, the similarity was greater as observed between $C$. nemorosa and Clusia melchiorii (60\%) (Barbosa et al., 2009).

This pattern is commonly observed in studies of fungi with a broad host range, in contrast to others that are restricted to one plant species, indicating a level of recurrence in the colonization of decaying plant debris (Parungao et al., 2002; Rambelli et al., 2004; Santana et al., 2005; Paulus et al., 2006b; Hyde et al., 2007; Monkai et al., 2013). There are significant differences among the constituents of leaf litter of different plant species, such as lignin, cellulose and secondary compounds as well as other components. Some of these compounds may inhibit fungal growth, whereas others require a variety of enzymes for their degradation (Vorísková and Baldrian, 2013). These differences in the components of leaves may contribute to differences in the composition and frequency of fungi that have been consistently identified among plant species in temperate (Ormeño et al., 2006; Allegrucci et al., 2014; Pasqualetti et al., 2014) and tropical forests (Paulus et al., 2003a; Rambelli et al., 2004; Paulus et al., 2006b; Magalhães et al., 2011; Monkay et al., 2013).

The spatial and temporal heterogeneity of the community is best viewed using NMDS, which reveals the tendency of the separation between the communities of the plant species (C and V), particularly between the wet (w) and dry (d) seasons (Figure 3). ANOSIM analysis reveals that the composition and richness of fungal communities were significantly different between plant species and seasons, and SIMPER analysis indicates that Pestalotiopsis spp., $P$. carolinensis, and sterile mycelium sp.6 were the taxa that contributed most to the dissimilarity between communities.

The NMDS data indicate that seasonality may serve as an important factor for the distribution of fungi when compared to the nature of the plant substrate. Clusia nemorosa and $V$. guianensis belong to different botanical families, Clusiaceae and Hypericaceae, respectively, but because they are phylogenetically related (APG III, 2009), this may favor the differences, similarities, or both observed among fungal communities. A different result was reported by Paulus et al. (2006b) who investigated the distribution of fungi from four phylogenetically unrelated botanical families (Elaeocarpaceae, Lauraceae, Moraceae, and Proteaceae) in a rainforest in Australia. These researchers found that the fungal community was more closely related to the plant species as a function of richness and community composition compared with seasonality, which is indicated by the low percentage of overlapping species (13-22\%). Allegrucci et al. (2014) obtained the same re- 
sults for fungi associated with Scutia buxifolia and Celtis tala in a xeric forest in Argentina.

In summary, the data presented here indicate that leaf litter in the Atlantic Forest contains a robust richness of fungi that differs depending on plant species and seasonality. Major differences in the fungal communities were observed between the wet and dry seasons when compared with the plant species of origin, because a significant number of fungi were shared between the two plants, likely because the plants belong to phylogenetically related botanical families and share certain biochemical characteristics such as latex production. According to Paulus et al. (2006b), adaptation of saprobic organisms to hostile environments such as tissues containing latex or phenolic compounds plays an important role in the development of recurrence in certain saprobic fungi. When fungal communities of phylogenetically distant plants were investigated, the plant species of origin was the most important factor influencing the compositions of communities (Paulus et al., 2006b). Although a core group of fungi was common to both plants, the majority of taxa were confined exclusively to one plant. Our results show a high recurrence of fungi to closely related plants that coexist in the same environment and show further that the saprobic fungal communities in rainforests are dynamic. Moreover, the factors that regulate such communities in the Atlantic Forest are complex.

\section{Acknowledgments}

The first author thanks the Coordenação de Aperfeiçoamento de Pessoal de Nível Superior (CAPES) for the award of a PhD scholarship and the "Programa de Pósgraduação em Botânica - PPGBot/UEFS $(\mathrm{CNPq} / \mathrm{MCTI})$." The authors thank the "Programa de Pesquisa em Biodiversidade - PPBio Semiárido" for financial support; and colleagues Carolina Azevedo, Josiane Monteiro, Lara Almeida and Tasciano Santa Izabel for technical assistance.

\section{References}

Allegrucci N, Bucsinszkya AM, Arturib M et al. (2014) Communities of anamorphic fungi on green leaves and leaf litter of native forests of Scutia buxifolia and Celtis tala: Composition, diversity, seasonality and substrate specificity. Rev Iberoam Micol doi 10.1016/j.riam.2013.11.002.

Angiosperm Phylogeny Group (2009) An update of the Angiosperm Phylogeny Group classification for the orders and families of flowering plants: APG III. Bot J Linn Soc 161:105-121.

Barbosa FR, Maia LC, Gusmão LFP (2009) Fungos conidiais associados ao folhedo de Clusia melchiorii Gleason e $C$. nemorosa G. Mey. (Clusiaceae) em fragmento de Mata Atlântica, BA, Brasil. Acta Bot Bras 23:79-84.

Bills GF, Polishook JD (1994) Abundance and diversity of microfungi in leaf litter of a lowland rain forest in Costa Rica. Mycol 86:187-198.
Buell CB, Weston WH (1947) Application of the mineral oil conservation method to maintaining collections fungus cultures. Am J Bot 34:555-561.

Cannon PF, Sutton BC (2004) Microfungi on wood and plant debris. In: Foster MS, Bills GF, Mueller GM (eds) Biodiversity of Fungi: Inventory and Monitoring Methods. Elsevier, Amsterdam, pp 217-239.

Castellani A (1967) Maintenance and cultivation of the common pathogenic fungal in sterile distilled water, for the researches. J Trop Med Hyg 70:181-184.

Chao A (1984) Non-parametric estimation of the number of classes in a population. Scand J Sta 11:265-270.

Cheewangkoon R, Groenewald JZ, Summerell et al. (2009) Myrtaceae, a cache of fungal biodiversity. Persoonia 23:5585.

Clarke KR (1993) Non-parametric multivariate analysis of changes in community structure. Aust J Ecol 18:117-143.

Core Team R (2013) R: A language and environment for statistical computing. R Foundation for Statistical Computing, Vienna, Austria.Available at: http://www.R-project.org. Accessed 20 February 2014.

Cornejo FH, Varela A, Wright J (1994) Tropical forest litter decomposition under seasonal drought: Nutrient release, fungi and bacteria. Oikos 70:183-190.

Hammer O, Harper DAT, Ryan PD (2013) Paleontological statistics, $\quad 1.34 \quad$ v. $\quad$ Available at: http://www.folk.uio.no/ohammer/past. Acessed May 9, 2014.

Hawksworth DL (2001) The magnitude of fungal diversity: The 1.5 million species estimate revised. Mycol Res 105:14221432.

Hyde KD, Bussaban B, Paulus B et al. (2007) Diversity of saprobic microfungi. Biodivers Conserv 16:7-35.

Jones EBG (2006) Form and function of fungal spore appendages. Mycoscience 47:167-183.

Kirby JJH, Webster J, Baker JH (1990) A particle plating method for analysis of fungal community composition and structure. Mycol Res 94:621-626.

Kodsueb R, Mckenzie EHC, Lumyong S et al. (2008) Diversity of saprobic fungi on Magnoliaceae. Fungal Divers 30:37-53.

Kriel WM, Swart WJ, Crous PW (2000) Foliar endophytes and their interactions with host plants, with specific reference to the Gymnospermae. Adv Bot Res 33:1-29.

Kruskall JB (1964) Nonmetric multidimensional scaling: A numerical method. Psychom 29:115-129.

Lacap DC, Hyde KD, Liew ECY (2003) An evaluation of the fungal 'morphotype' concept based on ribosomal DNA sequences. Fungal Divers 12:53-66.

Magalhães DMA, Luz EDMN, Magalhães AF et al. (2011) Riqueza de fungos anamorfos na serapilheira de Manilkara maxima, Parinari alvimii e Harleyodendron unifoliolatum na Mata Atlântica do Sul da Bahia. Acta Bot Bras 25:899907.

Magurran AE (1988) Ecological Diversity and its Measurement. Princeton, New Jersey.

McAleece N (1997) Biodiversity Profesional Beta I. The Natural History Museum \& The Scottish Association for Marine Science, London.

Monkai J, Promputtha I, Kodsueb R et al. (2013) Fungi on decaying leaves of Magnolia liliifera and Cinnamomum iners show litter fungi to be hyperdiverse. Mycosphere 4:292-301. 
Morris RJ (2010) Anthropogenic impacts on tropical forest biodiversity: A network structure and ecosystem functioning perspective. Philos Trans R Soc, Series B 365:3709-3718.

Myers N, Mittermeier RA, Mittermeier CG et al. (2000) Biodiversity hotspots for conservation priorities. Nat 403:853-845.

Nag Raj TR (1993) Coelomycetous Anamorphs with Appendage-Bearing Conidia. Mycologue Publications, Waterloo.

Neves MLC (2005) Caracterização da vegetação de um trecho de Mata Atlântica de Encosta na Serra da Jibóia, Bahia. Bahia, Brazil. M.Sc. Dissertation, Departamento de Ciências Biológicas, UEFS.

Ormeño E, Baldy V, Ballini C et al. (2006) Effects of environmental factors and leaf chemistry on leaf litter colonization by fungi in a Mediterranean shrubland. Pedobiol 50:1-10.

Parungao MM, Fryar SC, Hyde KD (2002) Diversity of fungi on rainforest litter in north Queensland, Australia. Biodiv Conserv 11:1185-1194.

Pasqualetti M, Mulas B, Rambelli A et al. (2014) Saprotrophic litter fungi in a Mediterranean ecosystem: Behaviour on different substrata. Plant Biosyst 148:342-356.

Paulus BC, Gadek P, Hyde K (2003a) Estimation of microfungi diversity in tropical rainforest leaf litter using particle filtration: The effects of leaf storage and surface treatment. Mycol Res 107:748-756.

Paulus BC, Gadek P, Hyde KD (2003b) Two new species of Dactylaria (anamorphic fungi) from Australian rainforests and an update of species in Dactylaria sensu lato. Fungal Divers 14:143-156.

Paulus BC, Gadek PA, Hyde KD (2006a) Successional Patterns of microfungi in fallen leaves of Ficus pleurocarpa(Moraceae) in an australian tropical rain forest. Biotropica 38:42-51.

Paulus BC, Kanowski J, Gadek PA, Hyde KD (2006b) Diversity and distribuition of saprobic microfungi in leaf litter of an Australian tropical rainforest. Mycol Res 110:1441-1454.

Polishook JD, Bills GF, Lodge DJ (1996) Microfungi from decaying leaves of two rain forest trees in Puerto Rico. J Industrial Microbiol 17:284-294.

Promputtha I, Hyde KD, McKenzie EHC et al. (2010) Can leaf degrading enzymes provide evidence that endophytic fungi becoming saprobes? Fungal Divers 41:89-99.

Rambelli A, Mulas B, Pasqualetti M (2004) Comparative studies on microfungi in tropical ecosystems in Ivory Coast forest litter: Behaviour on different substrata. Mycol Res 108:325-336.

Ribeiro MC, Metzger JP, Martensen AC et al. (2009) The brazilian Atlantic Forest: How much is left, and how is the remaining forest distributed? Implications for conservation. Biol Conserv 142:1141-1153.

Santana MS, Lodge DJ, Lebow P (2005) Relationship of host recurrence in fungi to rates of tropical leaf decomposition. Pedobiol 49:549-564.

Shanthi S, Vittal BPR (2012) Fungal diversity and the pattern of fungal colonization of Anacardium occidentale leaf litter. Mycol 3:132-146.

SOS Mata Atlântica (2013) Mata Atlântica. Available at: http://www.sosmatatlantica.org.br. Accessed 20 May 2014.

Thomas WWW, Carvalho AMV, Amorim AMA et al. (1998) Plant endemism in two forest in Southern Bahia, Brazil. Biodiv Conserv 7:311-322.

Trappe JM, Schenck NC (1982) Taxonomy of the fungi forming endomycorrhizae. In: Schenck, N.C. (ed) Methods and Principles of Mycorrhizal Research. The American Phytopathological Society, St. Paul, pp 1-9.

Unterseher M, Persoh D, Schnittler M (2013) Leaf-inhabiting endophytic fungi of European Beech (Fagus sylvaticaL.) co-occur in leaf litter but are rare on decaying wood of the same host. Fungal Divers 60:43-54.

Vorísková J, Baldrian P (2013) Fungal community on decomposing leaf litter undergoes rapid successional changes. ISME J 7:477-486.

Werneck MS, Pedralli G, Gieseke LF (2001) Produção de serapilheira em três trechos de floresta semidecídua com diferentes graus de perturbações na Estação Ecológica do Tripuí, Ouro Preto, MG. Rev Bras Bot 24:195-198.

Yanna Ho WH, Hyde KD (2001) Fungal communities on decaying palm fronds in Australia, Brunei and Hong Kong. Mycol Res 105:1458-1471.

Zhou D, Hyde KD (2001) Host-specificity, host-exclusivity, and host-recurrence in saprobic fungi. Mycol Res 105:14491457.

Associate Editor: Valeria Maia de Oliveira

All the content of the journal, except where otherwise noted, is licensed under a Creative Commons License CC BY-NC. 